\title{
Intrapericardial streptokinase in purulent pericarditis
}

\author{
Rajnish Juneja, Shyam S Kothari, Anita Saxena, Rajesh Sharma, Anuradha Joshi
}

\begin{abstract}
Six consecutive children with proven purulent pericarditis were treated with pericardial irrigation with streptokinase. Mean (SD) 861 (678) $\mathrm{ml}$ (range 240-2000) of thick purulent fluid was drained, and five children had complete clearance of the pus within 3-8 days. One child developed intrapericardial haemorrhage with a submitral pseudoaneurysm and underwent patch closure of the neck of the aneurysm as well as anterior pericardiectomy. Follow up of 13 to 30 months revealed no pericardial constriction. (Arch Dis Child 1999;80:275-277)
\end{abstract}

Keywords: purulent pericarditis; streptokinase

Purulent pericarditis has conventionally been managed with intravenous antibiotics and pericardial drainage. Although intrapericardial streptokinase instillation to facilitate drainage in purulent pericarditis was reported in a limited number of patients in the early $1950 \mathrm{~s},{ }^{1}$ these reports failed to generate any enthusiasm for this treatment until recently. ${ }^{2}$ We evaluated the role of intrapericardial streptokinase in purulent pericarditis.

\section{Patients and methods}

Six consecutive children (aged 8 months to 12 years (mean (SD) 5.95 (4.1) years; weight 6.5 to $25 \mathrm{~kg}$ (mean (SD) 13.3 (6.6)) were enrolled in the study. In all patients the diagnosis of purulent pericarditis had been confirmed by pericardial aspirate examination, and pericardiocentesis had led to incomplete fluid removal. Informed consent was obtained from the parents of all the children.

\section{STREPTOKINASE PROTOCOL}

Normal coagulation status was documented before the first instillation. Diluted streptokinase (10 000 to 15000 units $/ \mathrm{kg}$ ) was instilled every 12 hours through an $8 \mathrm{~F}$ pigtail catheter into the pericardium. The patient was rotated every 15 minutes and syringe aspiration done every two hours. Patients were clinically monitored for signs and symptoms of anaphylaxis, chest pain, arrhythmias, bleeding, and hypotension. Serial radiographs, haemoglobin measurements, clotting parameters, and echocardiography were carried out. Duration of streptokinase treatment was based on an estimate of pericardial fluid using echocardiography and amount of aspirate.

Intravenous antibiotics were started empirically and modified as per the culture reports and clinical response. At follow up, we evaluated patients clinically and by echoDoppler for evidence of persistent infection and pericardial constriction.

\section{Results}

Four patients had had symptoms suggesting acute pericardial collection for almost two weeks and had been feverish for nearly four weeks (mean (SD) 22 (7.6) days). There was evidence of an extracardiac infection in two patients (arthritis, osteomyelitis, and parietal abscesses). Staphylococcus aureus was isolated in blood or pericardial fluid cultures in four patients, but no organism was isolated in the other two.

Echocardiograms in five children showed an echodense collection suggestive of thick pus (fig 1) while one had an echolucent collection with no organisation. Pericardial aspirates were negligible in three patients while in the remaining three, $200-500 \mathrm{ml}$ of fluid was drained over 1-4 days before starting streptokinase. Mean (SD) pretreatment drainage volume was 178 (200) $\mathrm{ml}$ (range 15-540). In all patients, a large volume of thick purulent fluid was removed over the 3-8 days of streptokinase instillation (861 (678) $\mathrm{ml}$, range 240-2000) (fig 2). Table 1 summarises streptokinase doses and duration, and antibiotic treatment. In two children there was a sudden increase in pericardial fluid after streptokinase. Streptokinase could not be given for more than four doses in one child because of intrapericardial haemorrhage and later development of a submitral pseudoaneurysm. Streptokinase dosage ranged from 8000 to 15000 units $/ \mathrm{kg}$ for 4 to 8 days. In five patients, fever and systemic symptoms responded to various combinations of antibiotics; however, one child received empiric antitubercular treatment because of persistent fever and a positive Mantoux test.

Two patients developed a right atrial mass after starting streptokinase (noted on the 11 th and third days of antibiotic treatment, respectively) in the superior vena cava-right atrial junction. Amphotericin was used empirically in one child and the mass resolved over the subsequent three weeks. Spontaneous resolution occurred over three days in the other child.

One 8 year old boy (weight $14 \mathrm{~kg}$ ) with staphylococcal septicaemia and purulent pericarditis developed a submitral pseudoaneurysm during treatment. Intrapericardial streptokinase (150 000 units) was started on the fourth day, and $500 \mathrm{ml}$ of thick pus mixed with blood was aspirated. However, after four doses of streptokinase there was a sudden increase in the fluid with cardiac tamponade; we aspirated $300 \mathrm{ml}$ of frankly haemorrhagic fluid. Clotting 


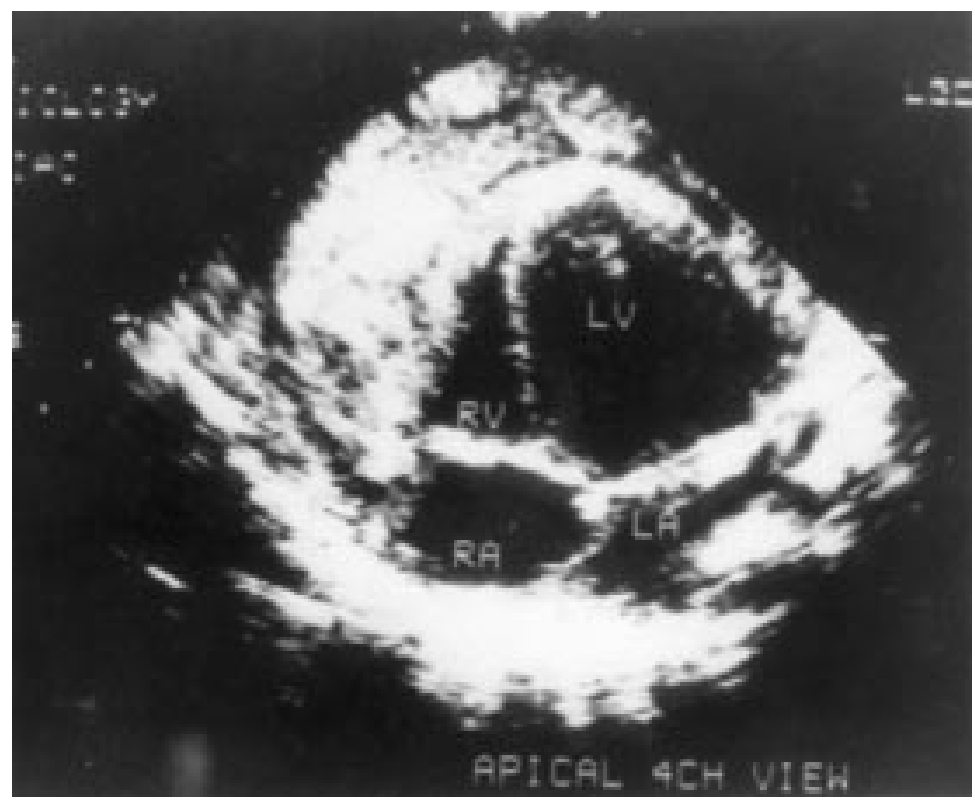

Figure 1 Apical four chamber view in patient 2 showing thick fibrinous intrapericardial exudates before streptokinase instillation. LA, left atrium; LV, left ventricle; $R A$, right atrium; $R V$, right ventricle.

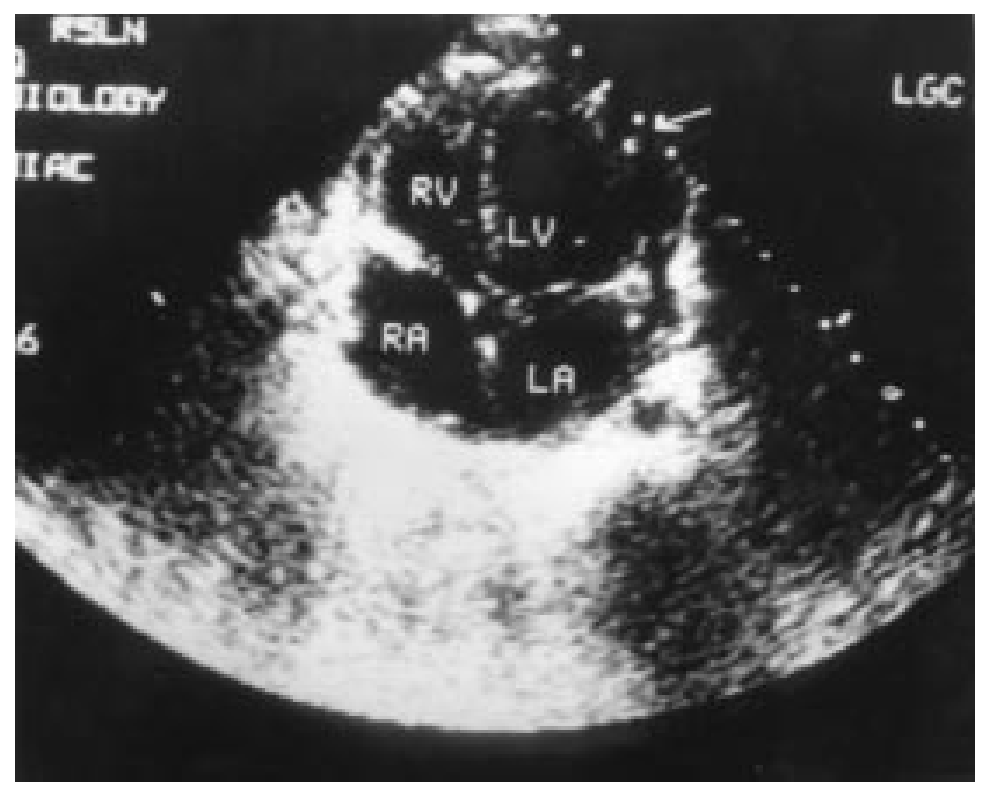

Figure 2 Apical four chamber view in patient 2 on the sixth day of streptokinase instillation. There is mild pericardial effusion with complete clearing of the echodense masses compared to the prestreptokinase picture (fig 1). Arrow, pigtail catheter in the pericardial space; $L A$, left atrium; $L V$, left ventricle; $R A$, right atrium; $R V$, right ventricle.

Table 1 Streptokinase and antibiotic regimens

\begin{tabular}{llll}
\hline $\begin{array}{l}\text { Weight } \\
(\mathrm{kg})\end{array}$ & Organism isolated & Antibiotics & $\begin{array}{l}\text { Streptokinase dose } \\
\text { (units)/duration }\end{array}$ \\
\hline 15 & Staphylococcus aureus & $\begin{array}{l}\text { Cloxacillin, gentamicin (NR) } \\
\text { Vancomycin (nephrotoxicity) } \\
\text { Cefotaxime, netilmicin } \\
\text { Amphotericin B }\end{array}$ & 150000,8 days \\
& & $\begin{array}{l}\text { C Penicillin, } \\
\text { cloxacillin }+ \text { gentamicin (NR) }\end{array}$ & 150000,8 days \\
10 & None & $\begin{array}{l}\text { Antitubercular treatment } \\
\text { Cloxacillin, amikacin }+ \text { ciprofloxacin }\end{array}$ & $\begin{array}{l}75000,4 \text { days } \\
75000,3 \text { days }\end{array}$ \\
9 & S aureus & Cloxacillin, amikacin, cefotaxime & 100000,3 days \\
6.5 & None & Cloxacillin, amikacin & 250000,6 days \\
25 & S aureus & Cloxacillin, amikacin (NR) & 150000,2 days \\
14 & S aureus & Vancomycin, cefotaxime & 75000,3 doses \\
\hline & & &
\end{tabular}

NR, no response. time was 15 minutes (basal 6 minutes). Streptokinase instillation was withheld but restarted (lower doses of 75000 units) after four days because of continuing fever and evidence of organisation. Although drainage increased to $300 \mathrm{ml}$ over the next two days, a submitral aneurysm was noted and streptokinase stopped. Review of a retrospective video recording showed a small intramyocardial echolucency in the submitral area on the second day of starting the first streptokinase course. Vancomycin and cefotaxime rapidly controlled the infection. However, evidence of constriction remained and the submitral pseudoaneurysm gradually increased in size. At open heart surgery the neck of the aneurysm was closed with a polytetrafluoroethylene patch and anterior pericardiectomy was done. Follow up at 13 months revealed complete regression of the pseudoaneurysm.

No patient had systemic bleeding, arrhythmias, or hypotension. There was no instance of infection at the site of pigtail insertion, nor was there any local pain during streptokinase instillation. Mean (SD) follow up of 19.8 (6.7) months (range 13-30) revealed no patient with pericardial constriction.

\section{Discussion}

We believe this is the first study to document the efficacy and safety of intrapericardial streptokinase in children with purulent pericarditis. Needle aspiration or catheter drainage alone is not sufficient to remove the infected fluid in most patients, but was attempted initially in all our patients. Intrapericardial streptokinase started as late as two to four weeks after the onset of illness despite the presence of adhesions and thick fluid (fig 1) was effective in draining the fluid. Reduced fibrinolytic activity in purulent pericarditis has been shown to cause extensive fibrin deposition over denuded mesothelial surfaces, and intrapericardial streptokinase helps in dissolving the fibrinous components of these exudates. ${ }^{3}$

This approach may have several advantages over surgical techniques. Limited procedures like subxiphoid drainage may not prevent acute constriction while more extensive procedures like pericardial window with a pleural drain and partial pericardiectomy both need a thoracotomy, which carries significant morbidity. ${ }^{4}$ Adequate surgical drainage prevents delayed constriction and even in our patients delayed constrictive pericarditis was not seen. Surgical approaches have a further disadvantage of requiring specialised care, which is scarce and costly in developing countries. In our children the cost of streptokinase was less than Rs4000 (US\$120) per patient.

We cannot fully explain the presence of a right atrial mass in two of our patients. A similar case was reported by Rao et al who speculated that decreased cardiac output was responsible for the thrombus. ${ }^{5}$ We believe this mass may be an infected collection seeping into the thin walled right atrium from the pericardium. Thrombolytic treatment may have influenced its occurrence. 
Submitral aneurysm following intrapericardial streptokinase has not been previously reported. Streptokinase stimulates interstitial collagen breakdown ${ }^{6}$ and it is possible that high local concentration might have led to the submitral aneurysm. This patient also had intrapericardial haemorrhage associated with deranged clotting time, suggesting systemic fibrinolysis. Berglin et al found no effect on fibrinogen, fibrin degradation products, or thrombin times after intrapleural instillation of streptokinase. $^{\text {? }}$

The choice of thrombolytic agent as well as doses and duration of treatment remains open. Winkler et al used urokinase ${ }^{2}$ while we preferred streptokinase because of its cost and familiarity.

We conclude that intrapericardial streptokinase is useful in treating purulent pericarditis.
Close clinical, haematological, and echocardiographic monitoring is warranted during its instillation.

1 Roy BB. Purulent pericarditis treated with streptokinasestreptodornase. F Indian Med Assoc 1954;24:264-5.

2 Winkler WB, Karnik R, Slany J. Treatment of exudative fibrinous pericarditis with intrapericardial urokinase. Lancet 1994;344:1541-2.

3 Leak LV, Ferrans VJ, Cohen SR, Eidbo EE, Jones M. Animal model of acute pericarditis and its progression to pericardial fibrosis and adhesions: ultrastructural studies. Am $\mathcal{7}$ Anat 1987;180:373-90.

4 Majid AA, Omar A. Diagnosis and management of purulent pericarditis: experience with pericardiectomy. $\mathcal{f}$ Thorac pericarditis: experience with peri

5 Rao DM, Singh S, Kumar L. Right atrial thrombus associated with pyopericardium. Indian Pediatr 1994;31:1427-9.

6 Peuhkurinen K, Risteli L, Jounela A, Risteli J. Changes in interstitial collagen metabolism during acute myocardial nfarction treated with streptokinase or tissue plasminogen activator. Am Heart F 1996;131:7-13.

7 Berglin E, Ekroth R, Teger-Nilsson AC, William-Olsson G. Intrapleural instillation of streptokinase: effects on systemic fibrinolysis. Thorac Cardiovasc Surg 1981;21:265-6. 